\title{
Primary peritoneal hepatoid adenocarcinoma: a diagnostic and therapeutic conundrum in patients with gastrointestinal bleeding
}

\author{
Faisal Inayat, ${ }^{1}$ Fahad Zafar, ${ }^{2}$ Hanan Tahir Lodhi, ${ }^{3}$ Waqas Ullah ${ }^{4}$
}

'Allama Iqbal Medical College, Lahore, Pakistan

${ }^{2}$ King Edward Medical University, Lahore, Pakistan ${ }^{3}$ University of Nebraska Medical Center, Omaha, Nebraska, USA ${ }^{4}$ Abington Hospital - Jefferson Health, Abington, Pennsylvania, USA

\section{Correspondence to}

Dr Faisal Inayat,

faisalinayat@hotmail.com

Accepted 31 August 2018

\section{DESCRIPTION}

A 50-year-old man with a history of iron-deficiency anaemia and fatty liver disease presented to the emergency department complaining of black tarry stools with associated weakness and shortness of breath for 1 week. At presentation, contrast-enhanced CT revealed multiple hypervascular masses in the abdomen and pelvis with the largest lesion located in the right lower quadrant, abutting the right psoas muscle (figure 1). Laboratory evaluation demonstrated a haemoglobin level of $5.5 \mathrm{~g} / \mathrm{dL}$ (normal, 13.5-17.5 g/dL). Upper endoscopy showed a mass, which was making an extrinsic impression into the stomach (figure 2). Colonoscopy was unremarkable for abnormalities. Endoscopic ultrasound-guided fine-needle aspiration (FNA) of the lesion adjacent to the stomach was performed using a 22-gauge needle (Expect Slimline; Boston Scientific, Natick, Massachusetts, USA). The FNA was positive for metastatic carcinoma with hepatic features. Furthermore, capsule endoscopy identified blood clots surrounding the multiple, small intestinal masses. These lesions were subsequently identified as the metastatic hepatoid adenocarcinoma (HAC) based on the histopathological findings.

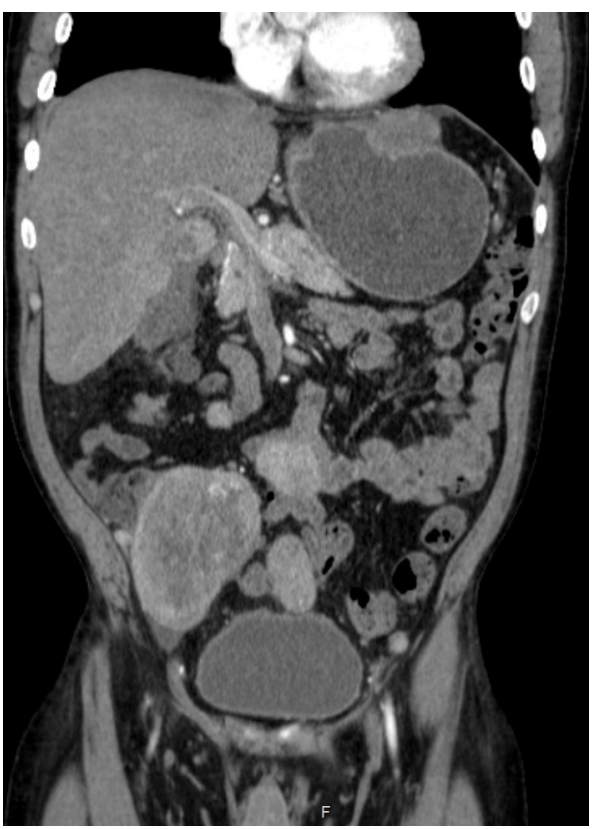

Figure 1 Contrast-enhanced CT abdomen and pelvis showing multiple peritoneal masses (coronal view).

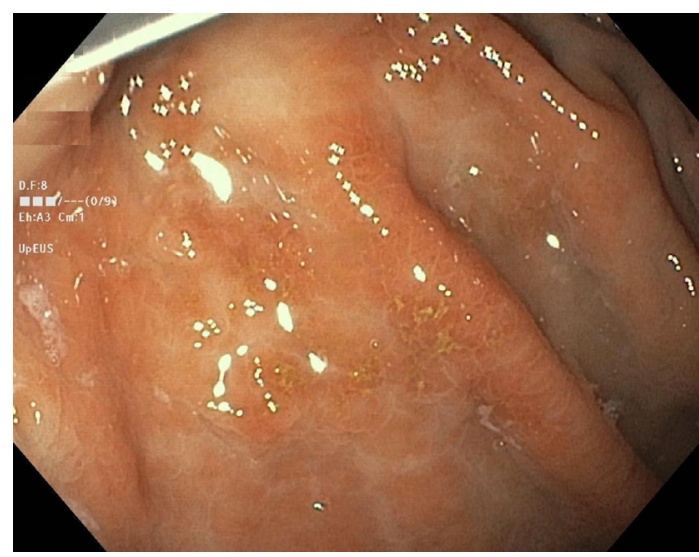

Figure 2 Esophagogastroduodenoscopy showing extrinsic impression on the fundus of the stomach.

The patient then underwent exploratory laparotomy with biopsy to establish the aetiology of the peritoneal mass. The pathological examination of the biopsy specimen from the peritoneal mass in the right lower quadrant showed hepatoid cells with abundant eosinophilic cytoplasm (figure 3). The cells were positive for hepatocyte-specific antigen (figure 4). Additionally, hepatocellular markers, including glypican-3, arginase-1, alpha-fetoprotein (AFP), alpha-1 antitrypsin, carcinoembryonic antigen and cytokeratins $8 / 18$ were also positive. His blood work revealed an AFP of $26000 \mathrm{ng}$ $\mathrm{mL}$ (normal, $<10 \mathrm{ng} / \mathrm{mL}$ ). Biopsy was considered consistent with metastatic hepatocellular carcinoma,

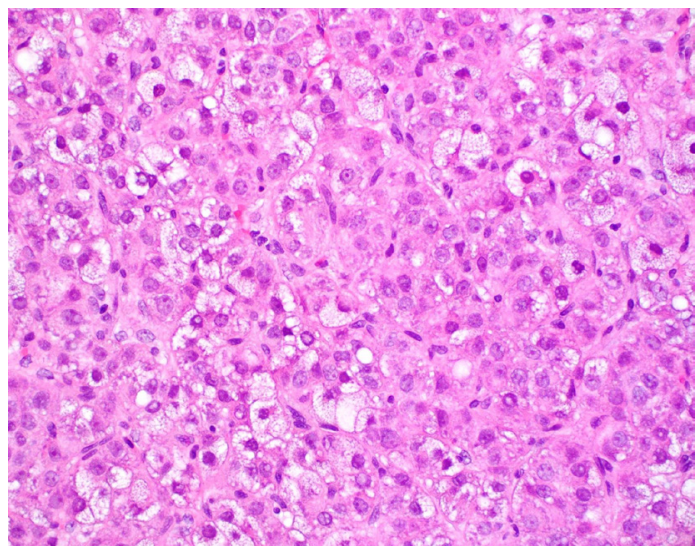

Figure 3 Pathological analysis of the peritoneal mass biopsy showing focal ballooned hepatoid cells having dense eosinophilic cytoplasm and large nuclei with minimal chronic inflammation (H\&E staining; 200x). 


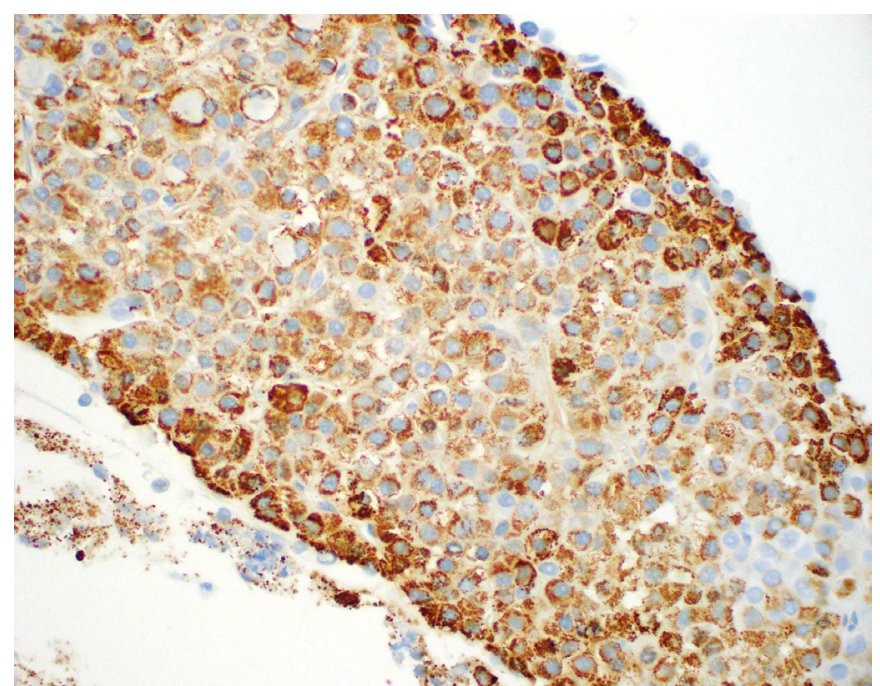

Figure 4 Histology of peritoneal biopsy showing positive staining for hepatocyte-specific antigen (hepatocyte paraffin antigen-1 staining; $200 x)$.

but there was no evidence of a primary liver lesion. Hence, the patient was diagnosed with primary peritoneal HAC. Unfortunately, the metastases were not amenable to surgical debulking; therefore, he was treated with $400 \mathrm{mg} /$ day sorafenib (Nexavar, Bayer). A subsequent CT scan showed progression of the disease. Therein, he was switched to docetaxel (Taxotere, Sanofi) for palliation that demonstrated a relatively good response.

$\mathrm{HAC}$ is a rare neoplasm with close morphological resemblance to hepatocellular carcinoma, without tumour in the liver. ${ }^{1}$ Primary peritoneal HAC is an extremely rare clinicopathological entity. To the best of our knowledge, only seven cases in adults have been reported as of July $2018 .^{2}$ Although the diagnosis of HAC is critical, clinicians frequently encounter difficulties in identifying these lesions. These tumours usually consist of large polygonal cells with abundant eosinophilic cytoplasm. While most hepatoid neoplasms express AFP, hepatocyte-specific antigen (hepatocyte paraffin-1) is considered to be more specific for hepatocellular differentiation. ${ }^{2}$ The data on the treatment of $\mathrm{HAC}$ are sparse, but existing literature confers a poor prognosis. ${ }^{3}$

It is notable that the gastrointestinal bleeding as an initial presentation of primary peritoneal HAC is unusually unique. In view of the potential risk of this neoplasm in patients with a new-onset gastrointestinal haemorrhage, as in the present case, gastrointestinal and/or peritoneal masses should be emergently

\section{Learning points}

- Hepatoid adenocarcinoma (HAC) is a rare extrahepatic adenocarcinoma that morphologically and immunophenotypically mimics hepatocellular carcinoma. To our research, this is the eighth documented case of primary peritoneal HAC in the literature.

- Differentiating primary peritoneal HAC from other tumours is a challenge and is also critical.

- Due to rarity and heterogeneity of primary peritoneal HAC, no standard treatment exists.

- The standard diagnostic and therapeutic algorithms are particularly warranted for these tumours, especially in patients with unusual initial presentations related to the gastrointestinal bleeding.

investigated using appropriate immunohistochemical markers for an early diagnosis and treatment to limit morbidity and mortality. Therefore, it is important for clinicians to have a broad differential in these types of presentations given the clinical implications.

Acknowledgements This case was presented as an abstract at the Annual Scientific Meeting of the American College of Gastroenterology, held on 13-18 October 2017 in Orlando, Florida, USA.

Contributors FI designed the study, performed the literature review, drafted the manuscript, reviewed the manuscript, revised the manuscript critically for important intellectual content and gave the final approval for the version published. FZ performed the literature review and drafted the manuscript. HTL reviewed the manuscript. WU contributed to the case presentation and suggested pertinent modifications.

Funding The authors have not declared a specific grant for this research from any funding agency in the public, commercial or not-for-profit sectors.

Competing interests None declared.

Patient consent Obtained.

Provenance and peer review Not commissioned; externally peer reviewed.

\section{REFERENCES}

1 Su JS, Chen YT, Wang RC, et al. Clinicopathological characteristics in the differential diagnosis of hepatoid adenocarcinoma: a literature review. World J Gastroenterol 2013; 19:321-7.

2 Oyan B, Sonmez O, Eren 00, et al. Primary peritoneal hepatoid adenocarcinoma: Response to platin based chemotherapy. J Clin Oncol 2016;34:e15667.

3 Xiao C, Wu F, Jiang H, et al. Hepatoid adenocarcinoma of the stomach: Nine case reports and treatment outcomes. Oncol Lett 2015;10:1605-9.

Copyright 2018 BMJ Publishing Group. All rights reserved. For permission to reuse any of this content visit

http://group.bmj.com/group/rights-licensing/permissions.

BMJ Case Report Fellows may re-use this article for personal use and teaching without any further permission.

Become a Fellow of BMJ Case Reports today and you can:

- Submit as many cases as you like

- Enjoy fast sympathetic peer review and rapid publication of accepted articles

- Access all the published articles

- Re-use any of the published material for personal use and teaching without further permission

For information on Institutional Fellowships contact consortiasales@bmjgroup.com

Visit casereports.bmj.com for more articles like this and to become a Fellow 